\title{
Dietary profile and phenolics consumption in university students from the Ningxia Hui Autonomous Region of China
}

\author{
Qinghan Gao ${ }^{1 *}$, Xiao Yuan ${ }^{1}$, Jianjun Yang ${ }^{1}$ and Xueyan $\mathrm{Fu}^{2}$
}

\begin{abstract}
Background: Polyphenol intake assessment is a first step for evaluating relationships between polyphenols and health-related outcomes. Ningxia Hui Autonomous Region is one of the minority areas in China, which is primarily consists of arid, dry desert.

Objectives: This study was to make assessment about phenolics intake by university students from Ningxia of China. Methods: This study employed data from a cross-sectional survey conducted from February to June 2018 in Ningxia Hui Autonomous Region of Northwest China. A total of 413 undergraduate students ( 143 boys, 270 girls), mean age 20.6 years, participated in the study. Food-frequency consumption and anthropometric measurements were included in the survey. According to phenol-explorer website, the amount of different classes of phenolic compounds were established. Statistics analyses were conducted with IBM SPSS 20.0.

Results: Profile of the student subjects showed low weight (19.1\%), overweight (6.8\%) and obesity (0.5\%). The mean value about phenolics intake was $1378 \mathrm{mg} /$ day. The main polyphenols consumed were flavonoids $(58.7 \%$ of total polyphenols), followed by phenolic acids (38.1\%). Vegetables, fruits and cereals products were the most consumed foods, while infusions and sugar products were lower. Fruit was the main food sources of total polyphenols, especially apple (22.95\%), orange juice (19.03\%) and apple juice (3.93\%).

Conclusions: This is the first study on the polyphenol intake of university students in Ningxia of China. The present results will be benefit for further investigation on the role of polyphenol intake against disease occurrence for this adults group.
\end{abstract}

Keywords: Polyphenols intake, Food sources, University students, Northwest China

\section{Background}

Traditional nutrition intervention has changed reasonably with food to provide health benefits and further prevent deficiencies occurrence. Some food components, such as phenolics as the nonnutrients in traditional nutrition science could provide health benefits. Nowadays polyphenols are best known more than just antioxidants

\footnotetext{
*Correspondence: gaoqinghan85@126.com

'School of Public Health and Management, Ningxia Medical University, Yinchuan 750004, Ningxia, China

Full list of author information is available at the end of the article
}

and also playing significant roles in reducing risk of various chronic diseases. Epidemiologists have suggested that phenolics may be against some chronic diseases, such as cardiovascular diseases [1], diabetes [2], cancer [3], and total mortality $[4,5]$. In vivo and in vitro evidences also demonstrates the relationship between large amounts of phenolics intake and reduced the risk of dislypidemia, atherosclerosis [6, 7], and inflammatory process refer to cardiovascular diseases [8]. But the previous research on health effects about phenolics mainly comes from the results get in vitro or in animals. Data

(c) The Author(s). 2020 Open Access This article is licensed under a Creative Commons Attribution 4.0 International License, which permits use, sharing, adaptation, distribution and reproduction in any medium or format, as long as you give appropriate credit to the original author(s) and the source, provide a link to the Creative Commons licence, and indicate if changes were made. The images or other third party material in this article are included in the article's Creative Commons licence, unless indicated otherwise in a credit line to the material. If material is not included in the article's Creative Commons licence and your intended use is not permitted by statutory regulation or exceeds the permitted use, you will need to obtain permission directly from the copyright holder. To view a copy of this licence, visit http://creativecommons.org/licenses/by/4.0/ The Creative Commons Public Domain Dedication waiver (http://creativecommons.org/publicdomain/zero/1.0/) applies to the data made available in this article, unless otherwise stated in a credit line to the data. 
for humans derived mainly from small trials, always involving in non-physiological polyphenols supplementation [9].

Dietary polyphenols are divided into four major classes, including phenolic acids, flavonoids, stilbenes and lignans, which are comprised of $>500$ different compounds with different structures in habitual human diets. Flavonoids are divided into six subfamilies including flavanols, flavanones, flavones, flavonols, isoflavones, and anthocyanidins according to the degree of oxidation of the oxygenated heterocycle which forms part of flavonoids structure [10]. For stilbenes, resveratrol is famous for its anti-carcinogenic effect [11]. Lignans is a group of complex phenolic polymer molecules with phytoestrogenic activity. Certain descriptive data about the intake of polyphenols is already available on the populationlevel. One previous study invested the work about dietary polyphenol intake of 36,037 adult subjects in Europe (including Denmark, France, Germany, Greece, Italy, Norway, Spain, Sweden, the Netherlands, and the UK), their results showed that factors such as sociodemographic, anthropometric as well as lifestyle were associated with the various intake of polyphenols [12].

Ningxia Hui Autonomous Region is one of the minority areas in China, which is located in northwest of China. Ningxia primarily consists of arid, dry desert. It is one of the poorest provinces in China. The average percapita income in Ningxia is RMB 3180, which was $23 \%$ below the mean national income [13]. Up to now, there is no descriptive total polyphenol intake study available in Ningxia, especially for university students there. College life is a critical period that can affect adult chronic diseases, so dietary intake during college may indicate adult lifestyle and health. Polyphenol intake assessment is a first step for evaluating relationships between polyphenols and health-related outcomes. Therefore, the evaluation of dietary patterns and identification of the intake of polyphenols among university students in Ningxia is important and might be helpful for interventions in promoting healthy eating behavior and preventing dietary-related diseases.

The present work was to estimate dietary polyphenols intake, and the main food contributions with food-frequency consumption and the Phenol-Explorer 3.0 for university students from China northwest [14]. This is helpful for promoting health education and public health for this group population. Knowledge of phenolics intakes among university students also might be useful for planning targeted prevention strategies at an early acceptable age.

\section{Methods}

\section{Participants}

This study employed data from a cross-sectional survey conducted from February to June 2018 in Ningxia Hui
Autonomous Region of Northwest China. A total of 413 undergraduate students (143 boys, 270 girls), mean age 20.6 years, participated in the study. The whole protocols study with students was fully approved by the scientific committee of Ningxia Medical University. All the students participated in the protocols were informed and consent for future use of questionnaire data. Subjects were informed of the aim of the research, and if they would like to participate, and collecting data with personal appointment.

\section{Nutritional survey}

A nutritional survey was conducted by trained staff with food frequency questionnaires (FFQ) and anthropometric measurements. A total of 49 food items were included in the FFQ, covering nine food groups (fruits, vegetables, infusions, cereals, dairy, bakery, sugars, meats and oils). The FFQ was examined by our skillful registered dietitians. The present FFQ used for polyphenol intake was established according to our previous validated FFQ in university students to assess the consumption frequency of foods and beverages, which were rich in polyphenols [15]. Phenol-Explorer 3.0 was applied for calculating polyphenol contents [14]. The energy calculated based on the China Food Composition Table [16]. During survey process, photo food models were used in order to standardize the types and amounts of the main food groups, such as fruits, vegetables, cereals, sugar, infusions, spoons, cups, as well as plates [17]. Physical activity has been defined the World Health Organization that any body movement produced in leisure time by skeletal muscles requiring energy consumption. In the present study, physical activity levels of the participants were classified into sedentary and moderated activity. The sedentary was the person reported with no leisure activity or done some activity not meeting the regular level. Moderated activity indicated moderate physical activities included yoga, walking at a brisk pace, cycling at a normal speed and lifting light objects [18].

\section{Anthropometric measurements}

According to the World Health Organization guidelines, anthropometric measurements were performed [19]. Weight and height were measured with electronic scales (Hochoice, EF07, China).

\section{Estimation of polyphenol intake}

According to Food Composition Tables in phenolexplorer website, the amounts of phenolic compounds belonging to different classes were established (http:// www.phenol-explorer.eu) [14]. For more than 400 foods, 35,000 values of 500 different polyphenols presented in Phenol-explorer website. More than 60,000 values phenolics content from more than 13,000 publications were 
critically evaluated, and then were included in the Phenol-explorer.eu database [12, 20]. Total polyphenol contents were calculated as the result of summing up the contents of individual compounds and expressed in $\mathrm{mg} / 100 \mathrm{~g}$ food weight. Foods such as noodles and orange fruit, their missing polyphenol contents can be extrapolated from wheat flour and orange juice, respectively.

\section{Statistical analysis}

Categorical variables including anthropometric results and physical activity level were showed as percentages. Continuous variables such as age, energy intake and basal metabolism rate (BMR) were presented as means \pm standard deviations (SD). Each food group contribution to the total phenolics intake and polyphenol subfamily classes was also showed as a percentage. The general linear model was used to analyze the intake of total polyphenols and polyphenol classes. $P<0.05$ was set up as the significant level. Statistics analyses were conducted with IBM SPSS 20.0.

\section{Results}

Profile of 413 university students are shown in Table 1. From anthropometric results, it can be found that low weight and obesity were coexisted. Referring to eating habits, this northwest region population has made remarkable progress in consuming industrialized foods instead of traditional preparation. Food consumption groups were shown in Fig. 1. Vegetables, fruits and cereals products were the three most consumed foods, while other important food groups such as infusions and sugar products were consumed less. From Table 2, it can be found that the main food sources of total polyphenols was fruits, especially apple (22.95\%), nonalcoholic beverages such as orange juice (19.03\%) and apple juice (3.93\%).

Table 1 Profile of the 413 university student subjects

\begin{tabular}{lllll}
\hline & Total & Boys & Girls & $\boldsymbol{P}$ \\
\hline Age $(\mathrm{y})$ & $21.0 \pm 1.7$ & $21.0 \pm 1.6$ & $21.3 \pm 1.7$ & $0.084^{\mathrm{a}}$ \\
Energy intake $(\mathrm{kcal} / \mathrm{d})$ & $1871 \pm 626$ & $1831 \pm 576$ & $1893 \pm 647$ & $0.163^{\mathrm{b}}$ \\
BMR (kcal/d) & $1473 \pm 176$ & $1683 \pm 117$ & $1362 \pm 166$ & $0.000^{\mathrm{b}}$ \\
BMl-for-Age (\%) & & & & $0.000^{\mathrm{b}}$ \\
$\quad$ Low weight & 19.1 & 8.4 & 24.8 & \\
Overweight & 6.8 & 14 & 3.0 & \\
Obesity & 0.5 & 0.0 & 0.7 & $0.426^{\mathrm{b}}$ \\
Physical Activity (\%) & & & & \\
Sedentary & 10.2 & 9.1 & 10.7 & \\
Moderated activity & 89.8 & 90.9 & 89.3 &
\end{tabular}

BMR Basal metabolic rate $(\mathrm{kcal} / \mathrm{d})$

Values expresses as mean \pm SD or $\%$

aT studen's test

${ }^{\mathrm{b}}$ Kruskal-Wallis test
The mean value of phenolics intake in these students was $1378 \mathrm{mg} /$ day. The distribution about the classes and subclasses of polyphenols was shown in Fig. 2. Flavonoids $(58.7 \%)$ contributed most for the total intake of phenolics. Phenolic acids contributed $38.1 \%$ of total intake of phenolics. Stilbenes and lignans accounted for < $3.2 \%$ of total polyphenol intake, and the mainly food sources were cereal products, whereas selected fruits and vegetables account of a smaller proportion for university students in China northwest. The present results were in line with Tetens et al. [21].

With regard to polyphenol subclasses, the three most important contributors to flavonoids subclasses intake were flavanols (38\%), flavonols (36\%) and flavanone. Hydroxycinnamic (96\%) and hydroxybenzoic acids were the two most contributors to phenolic acids. The values of polyphenol intake were higher in girls when compared with boys.

Table 2 list of the main sources of phenolics and the relative contribution of different foods item. In university students from the minority area of China, fruit and vegetables were the two important polyphenol contributors. Among them, apple (22.95\%) and orange juice $(19.03 \%)$ were the major dietary sources of polyphenols.

\section{Discussion}

Lifestyle and eating pattern have changed remarkably, which could be due to the progress made in technology and communication systems over the last decades [22].

Polyphenol intake was comparable with the mean intake in some Mediterranean countries, and similar the European Prospective Investigation into Cancer and Nutrition-Greece (1626 mg/day for women in Denmark) [12].

Flavonoids were mainly contributed by fruits and vegetables consumed for university students in Ningxia. Zhang et al. Estimated that the mean flavonol and flavone intakes were $14.30 \mathrm{mg} /$ day and $4.82 \mathrm{mg} /$ day, respectively in Chinese Adults [23]. One previous study suggested that intakes of total flavonoids, flavan-3-ols, flavanones and anthocyanidins were negatively associated with the risk of high CVD risk in USA adults [24, 25]. Feliciano group suggested that people who have a high consumption of flavonoids ( $\geq 788 \mathrm{mg} /$ day) could reduce the risk of all-cause mortality [26].

Phenolic acids were in consistence with former study, hydroxycinnamic acids were the most consumed subclass of phenolic acids. In this studied population, the intake of phenolic acids is lower than other research groups reported [27]. Phenolic acids were mainly contributed by infusions such as coffee and tea for university students of Ningxia.

Fruit and vegetables were the two important polyphenol contributors. One research in Chinese adults also 


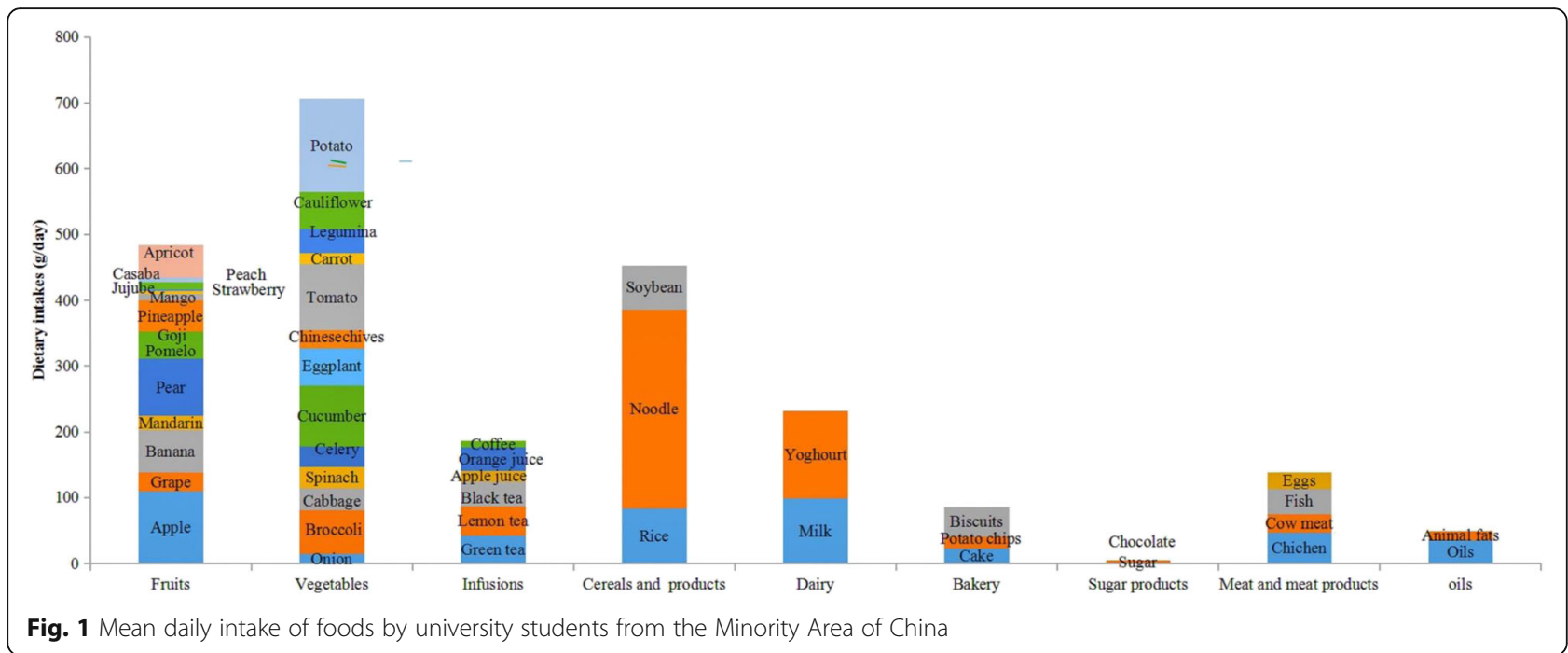

reported that apple was the main food sources of flavonols and flavones [23]. The present results is in line with the Australian population where apple was the important flavonoid source for young people [28], and the contribution of fruit to flavonoid intake was higher than that for vegetables [29].

Although some studies found that coffee was the major food source of polyphenols [24, 30,31], this was not the case in this studied population, as students drink less coffee in this place. In addition, one previous study also showed similar result that coffee contributed less about polyphenols, but fruit juice, sugar-sweetened beverage and water contributed much [32]. This could give the reason why fruit juices were the second largest contributions of polyphenols in this study.

Based on a recent study, the researchers identified median total polyphenol intake was found to be the lowest in Yucatan $(536 \mathrm{mg} /$ day) and the highest in Baja California $(750 \mathrm{mg} /$ day). The two main phenolics consumed were phenolic acids (56.3-68.5\% of total polyphenols) and flavonoids (28.8-40.9\% of total polyphenols) [33]. A previous study carried out in Italy reported that people with type 2 diabetes consumed $683.3 \pm 5.8 \mathrm{mg} /$ day of phenolics. The main dietary polyphenols source were non-alcoholic beverages, which account of $35.5 \%$ of total phenolics intake, followed by fruits (23.0\%), alcoholic

Table 2 Contribution of the main sources of polyphenol content in the diets of university students

\begin{tabular}{|c|c|c|c|c|}
\hline Food & $\begin{array}{l}\text { Mean intake }(g / \\
\text { d) }\end{array}$ & $\begin{array}{l}\text { Polyphenols content }(\mathrm{mg} / 100 \\
\text { g) }\end{array}$ & $\begin{array}{l}\text { Polyphenols contributed by mean intake } \\
\text { (mg) }\end{array}$ & $\begin{array}{l}\text { Relative contribution } \\
(\%)\end{array}$ \\
\hline Apple & 109.15 & 296.3 & 323.41 & 22.95 \\
\hline Grape & 28.66 & 201.0 & 57.61 & 4.09 \\
\hline Banana & 65.03 & 90.4 & 58.79 & 4.17 \\
\hline Pear & 87.43 & 71.0 & 62.08 & 4.41 \\
\hline Pineapple & 47.16 & 94.3 & 44.47 & 3.16 \\
\hline Broccoli & 66.39 & 101.6 & 67.45 & 4.79 \\
\hline Spinach & 32.76 & 91.0 & 29.81 & 2.11 \\
\hline Cucumber & 91.54 & 19.5 & 17.85 & 1.27 \\
\hline Eggplant & 56.61 & 87.0 & 49.25 & 3.49 \\
\hline Tomato & 100.87 & 68.0 & 68.59 & 4.87 \\
\hline Potato & 142.31 & 38.0 & 54.08 & 3.84 \\
\hline Green tea & 42.32 & 65.8 & 27.85 & 1.98 \\
\hline Black tea & 37.33 & 80.5 & 30.05 & 2.13 \\
\hline Apple juice & 16.37 & 339.0 & 55.49 & 3.93 \\
\hline $\begin{array}{l}\text { Orange } \\
\text { juice }\end{array}$ & 35.53 & 755.0 & 268.25 & 19.03 \\
\hline
\end{tabular}




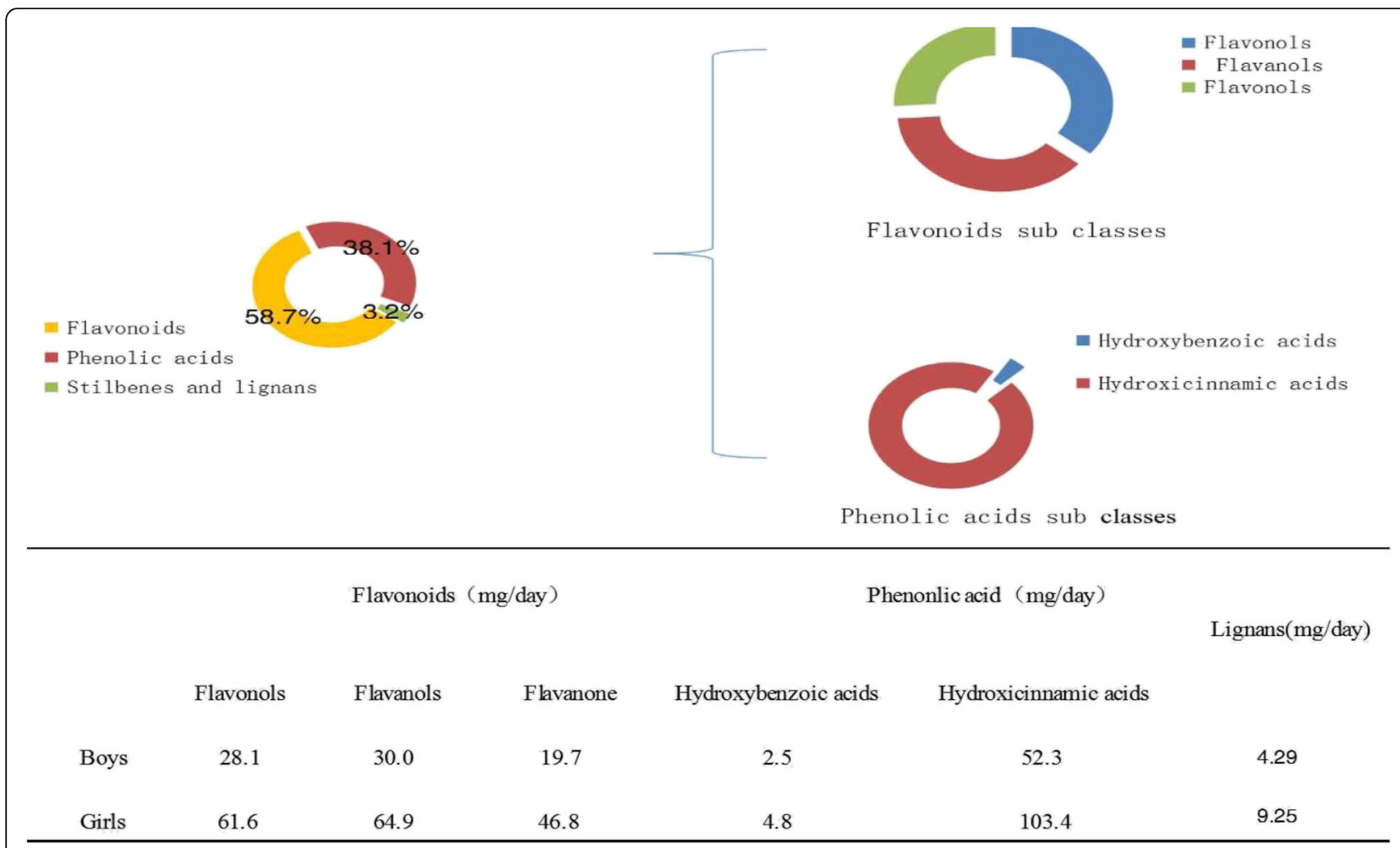

Fig. 2 Phenolic compounds intake, classes and sub classes distribution

beverages $(14.0 \%)$, vegetables $(12.4 \%)$, tubers and cereal products $(4.6 \%)$, legumes $(3.7 \%)$ as well as oils $(2.1 \%)$. Chocolates, cakes and nuts were three negligible sources of polyphenols in this cohort. Flavonoids (47.5\%) and phenolic acids $(47.4 \%)$ contribute much to the total phenolics intake [34]. Another study from Brazil revealed that the mean total phenolics intake was $1198.6 \mathrm{mg} /$ day. Phenolic acids $(729.5 \mathrm{mg} /$ day) and flavonoids $(444.7 \mathrm{mg} /$ day) also were the two main polyphenol classes. Coffee (45.8\%), beans $(32.8 \%)$ and polenta $(1.3 \%)$ were the three larger dietary contributors for total phenolics consumed there [35]. For the group of elderly Japanese, their average total polyphenol intake was around $1492 \mathrm{mg} /$ day, of which beverages $(79.1 \%)$ contributed as the greatest part [36].

Compared to previous studies in which men had higher total polyphenol intake than women [15, 22], especially for flavonoids [37], girls had a higher intake than boys in this study.

At present, although modernization happened in some regions of the world, healthy eating styles are maintained such as the mediterranean daily diet, which contains foods rich in phenolics. The updated dietary guidelines showed herbal infusions, fruits and vegetables are at the base. Therefore, it proposes educational strategies for further implementation of the updated recommendations. From this aspect, nutritional education should take actions and incorporate with food and this will be benefit for the young population.
Despite of different studies on polyphenols intakes were done in some countries, no previous work of this kind was done in China. Up to now, there is no descriptive total polyphenol intake research available in Ningxia, which is located in China northwest, especially for university students there. College life is a critical period that can affect adult chronic diseases, so dietary intake during college may indicate adult lifestyle and health. It is a first step for evaluating relationships between phenolics and health-related outcomes through proper evaluation of phenolics intake.

Two strengths of this study were the special participants and the use of Phenol-Explorer, which is an extensive food composition database and include a complete list of 500 polyphenols. But there was also some limitations in our study. It was likely underestimation of true phenolics intake due to miss some regional foods data. All subjects involved in this study were university students and therefore very low education people or adults were recruited, so the present results cannot be totally generalisable.

\section{Conclusions}

Intake of total polyphenol was $1378 \mathrm{mg} /$ day. Main food sources of polyphenols were fruits, especially apple (22.95\%), orange juice (19.03\%) and apple juice (3.93\%). These results show significant importance of promoting 
a healthier diet intake in young adults with more fruits, vegetables and nuts to increase the currently relatively lower polyphenol intakes. Research on young populations intakes of polyphenols will be useful for recommendations establishment for this group. The present results will be benefit for further investigation on the role of polyphenol intake against disease occurrence for young population.

\section{Acknowledgements}

Not applicable.

\section{Authors' contribution}

Qinghan Gao designed the research; Xiao Yuan collected the data; Jianjun Yang performed the statistical analysis; Xueyan Fu drafted the manuscript. All authors have read and approved the final version of the manuscript.

\section{Funding}

This work was supported by Scientific Research Project for Universities in Ningxia, China (grant no. NGY2018-71); Natural Science Foundation of Ningxia, China (grant no. 2018AAC03094); and The Third Batch of Ningxia Youth Talents Supporting Program (grant no. TJGC2018084). All the funders did not have involvement in the study design, data collection, data analysis and write-up of this study.

\section{Availability of data and materials}

The datasets used and/or analysed during the current study are available from.

the corresponding author on reasonable request

\section{Ethics approval and consent to participate}

The whole protocols study with students was fully approved by the scientific committee of Ningxia Medical University. All the students participated in the protocols were informed and consent for future use of questionnaire data. Written consent from the students of the university was given by signing a form.

\section{Consent for publication}

Not applicable.

\section{Competing interests}

The authors declare that there are no conflicts of interest.

\section{Author details}

${ }^{1}$ School of Public Health and Management, Ningxia Medical University, Yinchuan 750004, Ningxia, China. ${ }^{2}$ School of Pharmacy, Ningxia Medical University, Yinchuan 750004, China.

Received: 18 October 2019 Accepted: 24 September 2020

Published online: 18 November 2020

\section{References}

1. van Dam RM, Naidoo N, Landberg R. Dietary flavonoids and the development of type 2 diabetes and cardiovascular diseases: review of recent findings. Curr Opin Lipidol. 2013;24:25-33.

2. Zamora-Ros R, Forouhi NG, Buijsse B, Schouw van der $Y T$, Boeing $H$, Feskens EJM. The association between dietary flavonoid and lignan intakes and incident type 2 diabetes in European population: the EPIC-InterAct study. Diabetes Care. 2013;36:3961-70.

3. Zamora-Ros R, Touillaud M, Rothwell JA, Romieu I, Scalbert A. Measuring exposure to the polyphenol metabolome in observational epidemiologic studies, current tools and applications and their limits. Am J Clin Nutr. 2014; 100:11-26.

4. Zamora-Ros R, Jimenez C, Cleries R, Agudo A, Sanchez MJ, SanchezCantalejo $\mathrm{E}$, et al. Dietary flavonoid and lignan intake and mortality in a Spanish cohort. Epidemiology. 2013;24:726-33.

5. Ivey KL, Hodgson JM, Croft KD, Lewis JR, Prince RL. Flavonoid intake and allcause mortality. Am J Clin Nutr. 2015;101:1012-20.
6. Delmas D, Jannin B, Latruffe N. Resveratrol: preventing properties against vascular alterations and ageing. Mol Nutr Food Res. 2005:49:377-95.

7. Santos CN, Gomes A, Oudot C, Dias-Pedroso D, Rodriguez-Mateos A, Vieira C. Pure polyphenols applications for cardiac health and disease. Curr Pharm Des. 2018;24:2137-56

8. Z Zhang C, Lin GS, Wan WG, Li XY, Zeng B, Yang B, et al. Resveratrol: a polyphenol phytoalexin, protects cardiomyocytes against anoxia/ reoxygenation injury via the TLR4/NF-kB signaling pathway. Int J Mol Med. 2012:29:557-63.

9. Cui C, Birru RL, Snitz BE, Ihara M, Kakuta C, Lopresti BJ, et al. Effects of soy isoflavones on cognitive function: a systematic review and meta-analysis of randomized controlled trials. Nutr Rev. 2019:1-11.

10. Tsao R. Chemistry and biochemistry of dietary polyphenols. Nutrients. 2010; 2:1231-46.

11. Rauf A, Imran M, Butt MS, Nadeem M, Peters DG, Mubarak MS. Resveratrol as an anti-cancer agent: a review. Crit Rev Food Sci Nutr. 2018;58:1428-47.

12. Zamora-Ros R, Knaze V, Rothwell JA, Hémon B, Moskal A, Overvad K, et al. Dietary polyphenol intake in Europe: the European prospective investigation into cancer and nutrition (EPIC) study. Eur J Nutr. 2016:55:1359-75.

13. National Bureau of Statistics of China. China statistical yearbook. Beijing: China Statistics Press; 2008. p. 341.

14. Rothwell JA, Perez-Jimenez J, Neveu V, Medina-Remón A, M'Hiri N, GarcíALobato $P$, et al. Phenol-Explorer 3.0: a major update of the Phenol-Explorer database to incorporate data on the effects of food processing on polyphenol content. Database (Oxford). 2013:bat070.

15. xiaofen Z. Investigation on dietary polyphenol intake among college students of Yinchuan [D]. Yinchuan: Ningxia Medical University; 2018. (In Chinese).

16. Institute of Nutrition and Health, Chinese Center for Disease Control and Prevention. China food composition book 1. 6nd ed. Beijing: Peking University Medical Press; 2018.

17. Rossi MC, Bassett MN, Sammán NC. Dietary nutritional profile and phenolic compounds consumption in school children of highlands of argentine northwest. Food Chem. 2018;238:111-6.

18. Ainsworth BE, Haskell WL, Herrmann SD, Meckes N, Bassett DR Jr, TudorLocke C, et al. Compendium of physical activities: a second update of codes and MET values. Med Sci Sports Exerc. 2011;43:1575-81.

19. WHO. Physical status, the use and interpretation of anthropometry. Report of a WHO Expert Committee. World Health Organ Tech Rep Ser. 1995;854: $1-452$.

20. Neveu V, Perez-Jimenez J, Vos F, Crespy V, du Chaffaut L, Mennen L, et al. Phenol-explorer: an online comprehensive database on polyphenol contents in foods. Database (Oxford). 2010.

21. Tetens I, Turrini A, Tapanainen H, Christensen T, Lampe JW, Fagt S, Hakansson $\mathrm{N}$, Lundqvist A, Hallund J, Valsta LM. Dietary intake and main sources of plant lignans in five European countries. Food Nutr Res. 2013;57:1-10.

22. Ningxia statistical Bureau. Ningxia statistical yearbook. Beijing: China Statistics Press; 2013. (in Chinese)

23. Zhang Y, Li Y, Cao C, Cao J, Chen W, Zhang Y, Wang C, Wang J, Zhang X, Zhao $X$. Dietary Flavonol and flavone intakes and their major food sources in Chinese adults, Nutr. Cancer. 2010:62:1120-7.

24. Sebastia RS, Enns CW, Goldman JD, Moshfegh AJ. Dietary flavonoid intake is inversely associated with cardiovascular disease risk as assessed by body mass index and waist circumference among adults in the United States. Nutrients. 2017:9:827.

25. Feliciano RP, Pritzel S, Heiss C, Rodriguez-Mateos A. Flavonoid intake and cardiovascular disease risk. Curr Opin Food Sci. 2015:2:92-9.

26. Krupp D, Remer T, Penczynski KJ, Bolzenius K, Wudy SA, Buyken AE. Relevance of fruits, vegetables and flavonoids from fruits and vegetables during early life, mid-childhood and adolescence for levels of insulin-like growth factor (IGF-1) and its binding proteins IGFBP-2 and IGFBP-3 in young adulthood. Br J Nutr. 2016;115:527-37.

27. Johannot L, Somerset SM. Age-related variations in flavonoid intake and sources in the Australian population. Public Health Nutr. 2006:9:1045-54.

28. Penczynski KJ, Herder C, Krupp D, Rienks J, Egert S, Wudy SA, et al. Flavonoid intake from fruit and vegetables during adolescence is prospectively associated with a favourable risk factor profile for type 2 diabetes in early adulthood. Eur J Nutr. 2019:58:1159-72.

29. Miranda AM, Steluti J, Fisberg RM, Marchioni DM. Dietary intake and food contributors of polyphenols in adults and elderly adults of Sao Paulo: a population-based study. Br J Nutr. 2016;115:1061-70. 
30. Perez-Jimenez J, Fezeu L, Touvier M, Arnault N, Manach C, Hercberg S, et al. Dietary intake of 337 polyphenols in French adults. Am J Clin Nutr. 2011;93: $1220-8$.

31. Wisnuwardani RW, Henauw SD, Androutsos O, Forsner M, Gottrand F, Huybrechts I, et al. Estimated dietary intake of polyphenols in European adolescents: the HELENA study. Eur J Nutr. 2019:58(6):2345-63.

32. Zamora-Ros R, Andres-Lacueva C, Lamuela-Raventos RM, Berenguer T, Jakszyn P, Barricarte A, et al. Estimation of dietary sources and flavonoid intake in a Spanish adult population (EPIC-Spain). J Am Diet Assoc. 2010 110:390-8.

33. Zamora-Ros R, Biessy C, Rothwell JA, Monge A, Lajous M, Scalbert A. Dietary polyphenol intake and their major food sources in the Mexican teachers' cohort. Br J Nutr. 2018;120:353-60.

34. Vitale M, Masulli M, Rivellese A, Bonora E, Cappellini A, Nicolucci S, et al. Dietary intake and major food sources of polyphenols in people with type 2 diabetes: the TOSCA.IT study. Eur J Nutr. 2018;57:679-88.

35. Nascimento-Souza MA, Paiva PG, Pérez-Jiménez J, Franceschini SCC, Ribeiro $A Q$. Estimated dietary intake and major food sources of polyphenols in elderly of Visosa, Brazil: a population-based study. Eur J Nutr. 2018;57:61727.

36. Taguchi C, Fukushima Y, Kishimoto Y, Suzuki-Sugihara N, Saita E, Takahashi $Y$, et al. Estimated dietary polyphenol intake and major food and beverage sources among elderly Japanese. Nutrients. 2015;7:10269-81.

\section{Publisher's Note}

Springer Nature remains neutral with regard to jurisdictional claims in published maps and institutional affiliations.

Ready to submit your research? Choose BMC and benefit from:

- fast, convenient online submission

- thorough peer review by experienced researchers in your field

- rapid publication on acceptance

- support for research data, including large and complex data types

- gold Open Access which fosters wider collaboration and increased citations

- maximum visibility for your research: over $100 \mathrm{M}$ website views per year

At $\mathrm{BMC}$, research is always in progress.

Learn more biomedcentral.com/submissions 